\title{
OPTIMAL SOLAR POWERED SYSTEM FOR LONG HOUSES IN SARAWAK BY USING HOMER TOOL
}

\author{
Mohd Amran Mohd Radzi ${ }^{1}$, Nasrudin Abd. Rahim ${ }^{2}$, Hang Seng Che ${ }^{2}$, Hideaki \\ Ohgaki $^{3}$, Hooman Farzaneh ${ }^{3}$, Wallace Shung Hui Wong ${ }^{4}$, and Lai Chean Hung ${ }^{4}$ \\ ${ }^{1}$ Department of Electrical and Electronic Engineering, Universiti Putra Malaysia, Selangor, Malaysia, \\ e-mail: amranmr@upm.edu.my \\ ${ }^{2}$ UM Power Energy Dedicated Advanced Centre, University of Malaya, Kuala Lumpur, Malaysia, \\ e-mail: nasrudin@um.edu.my, hsche@um.edu.my \\ ${ }^{3}$ Institute of Advanced Energy, Kyoto University, Kyoto, Japan, \\ e-mail: ohgaki.hideaki.2w@kyoto-u.ac.jp, hooman.farzaneh.2v@kyoto-u.ac.jp \\ ${ }^{4}$ Faculty of Engineering, Computing and Science, Swinburne University of Technology Sarawak Campus, \\ Sarawak, Malaysia, e-mail: wwong@swinburne.edu.my, clai@swinburne.edu.my
}

Received Date: August 20, 2018; Revised Date: February 13, 2019; Acceptance Date: March 13, 2019

\begin{abstract}
Ensuring electricity coverage for rural areas in Malaysia is still a big challenge due to the houses are in deep forest and scattered locations. The estimated coverage in 2015 is only $94 \%$ and still depending on conventional fossil-fuel generators. Considering full utilization of renewable source is highly recommended. Therefore, this paper proposes optimal design of full solar powered system for long houses in one selected area in Sarawak, Malaysia. Interestingly, the work has been started with evaluation and estimation of loads with site survey done to the selected area, which is Kampung Sungai Merah. The site visit has been conducted to survey and estimate the loads at the site. The design considers meteorological and climate data, specifications of system, and simulation configuration. HOMER tool is used in this work which comes with the optimization algorithm to search for the least cost system. The simulation results reveal the outcomes by considering three discount rates of $3 \%, 6 \%$ and $12 \%$, and the system is presented with the best design for each rate. Lower discount rate contributes to higher PV and lower battery architectures as compared to higher discount rates. In short, it can be concluded that the system is optimally designed to be fully depended on utilization of solar as solid renewable source, which affects PV and battery architectures as two key design elements. Finally, this work should be able to provide the designer an opportunity to fully consider various options in developing the best renewable and full solar powered system for rural electrification.
\end{abstract}

Keywords: HOMER, Optimization, Photovoltaic, Renewable energy, Rural, Solar

\section{Introduction}

Long houses are a famous type of residential houses for most villages in Sarawak, located in East Malaysia. Due to their locations are in deep forest and scattered locations with small group of families staying there, quite difficult for those villages to be supplied with electrical power supply from the main grid operated by Sarawak Energy Berhad (SEB). Thus, this existing situation causes most rural areas have been electrified by conventional fossil-fuel generators, or with the latest initiative by the government, by implementing renewable systems. However, there is still wide opportunity for improving electricity coverage in Sarawak. The estimated coverage in 2015 is only $94 \%$, and to be targeted to achieve $99.9 \%$ in 2020 [1].

Developing renewable energy systems by using software tool is considered as the latest approach, especially by using Hybrid Optimization of Multiple Energy Resources 
(HOMER) [2]. This software navigates the complexities of building cost effective and reliable microgrids that combine traditionally generated and renewable power sources, storage and load management. Use of HOMER somehow helps the designer later to properly design the work as it covers various considerations including weather and environmental data, load estimation, and appropriate choice of component for the system.

In related to significant works on photovoltaic (PV) alone as renewable resource, there are many works on using HOMER in designing the supply systems such as to power up directly rural or remote area [3], or specific facilities such as health clinic [4], water pumping system [5] and reverse osmosis plant [6]. Besides that, in some of previous works, although comprehensive works are done with detailed analysis [7-8], estimation is only done to the loads without having real view of the selected sites. In other means, the works focus on the real sources of power rather than on real demand. In specific area like Sarawak where locations of the village or rural houses are scattered, having understanding on the locations, further with specific design of houses, seems to be necessary.

Therefore, this study covers optimal design of PV system for rural electrification. The first part covers evaluation of the selected rural house located at Kampung Sungai Merah, Sebuyau, Sarawak. The loads are surveyed through site visit, further is estimated for one-year usage. Then, design stage is carried out by considering meteorological and climate data, identifying specifications of system, and simulation configuration. HOMER software tool used in this work comes with the optimization algorithm to search for the least cost system. Then, assessment will be carried out comprehensively to obtain the most optimal output.

Next section later will cover site visit and estimation of loads, and followed by design and assessment. Then, the results are presented and finally conclusion of the outcomes.

\section{Site Visit and Estimation of Loads}

Location of Kampung Sungai Merah is shown in Figure 1, which is located at latitude of $1.51^{\circ} \mathrm{N}$ and longitude of $110.9^{\circ} \mathrm{E}$. The site visit to Kampung Sungai Merah was carried out by the team from University of Malaya Power Energy Dedicated Advanced Centre (UMPEDAC) and Swinburne University of Technology Sarawak Campus. The Iban long house at Kampung Sungai Merah consists of 3 households, powered by two 3-kW diesel generators, as shown in Figure 2. One of the generators is supplying electricity to House 1, while Houses 2 and 3 are jointly supplied by another generator.

According to the visit, the electricity usage in these long houses looks quiet primitive, where the villagers do not use appliances with high power consumption like freezer, refrigerator and electric kettle. Electricity is mainly used for lightings and fans, as well as for entertainment (television). The electrical loads are listed in Table 1 . The average is estimated accordingly by considering active usage of each load per day, which leads to the total energy consumption per day is $3.97 \mathrm{kWh}$.

\section{Design and Assessment using HOMER}

The flow of work in designing the system is shown in Figure 3. Components to be proposed for the system must be determined first. The proposed system contains loads which will be supplied by PV source, and battery is configured for storage purpose. The system is purely based on renewable source, and therefore, by properly configuring the components according to demand of the selected area and simulated by HOMER, the system should be 
able to provide sustainable supply later. After selecting the components, the next stage is to determine parameters of the components and set their values. In addition, this stage also includes obtaining meteorological and climate data. Then, all the values and data will become inputs needed by HOMER, which should be configured accordingly.

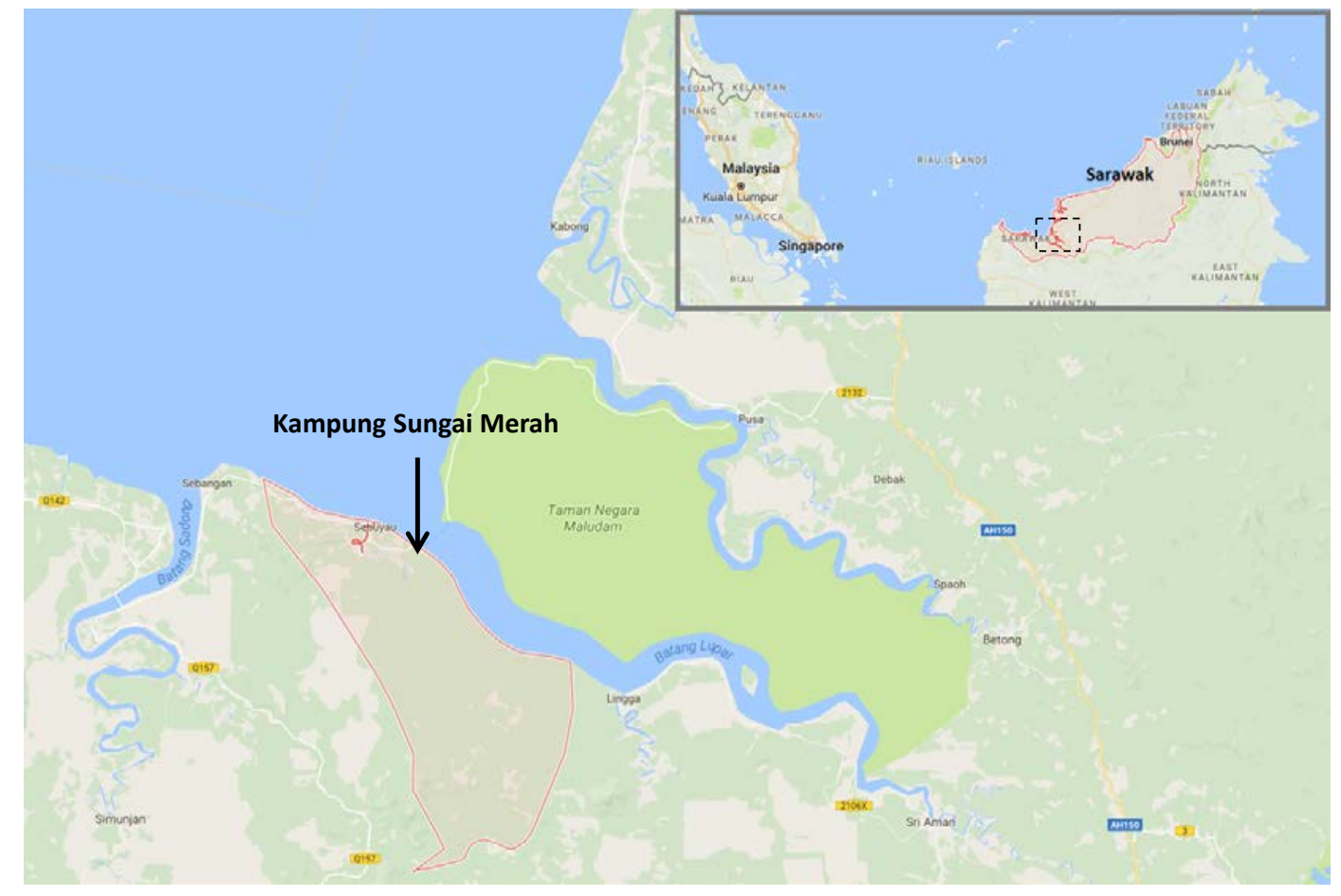

Figure 1. Location of Kampung Sungai Merah

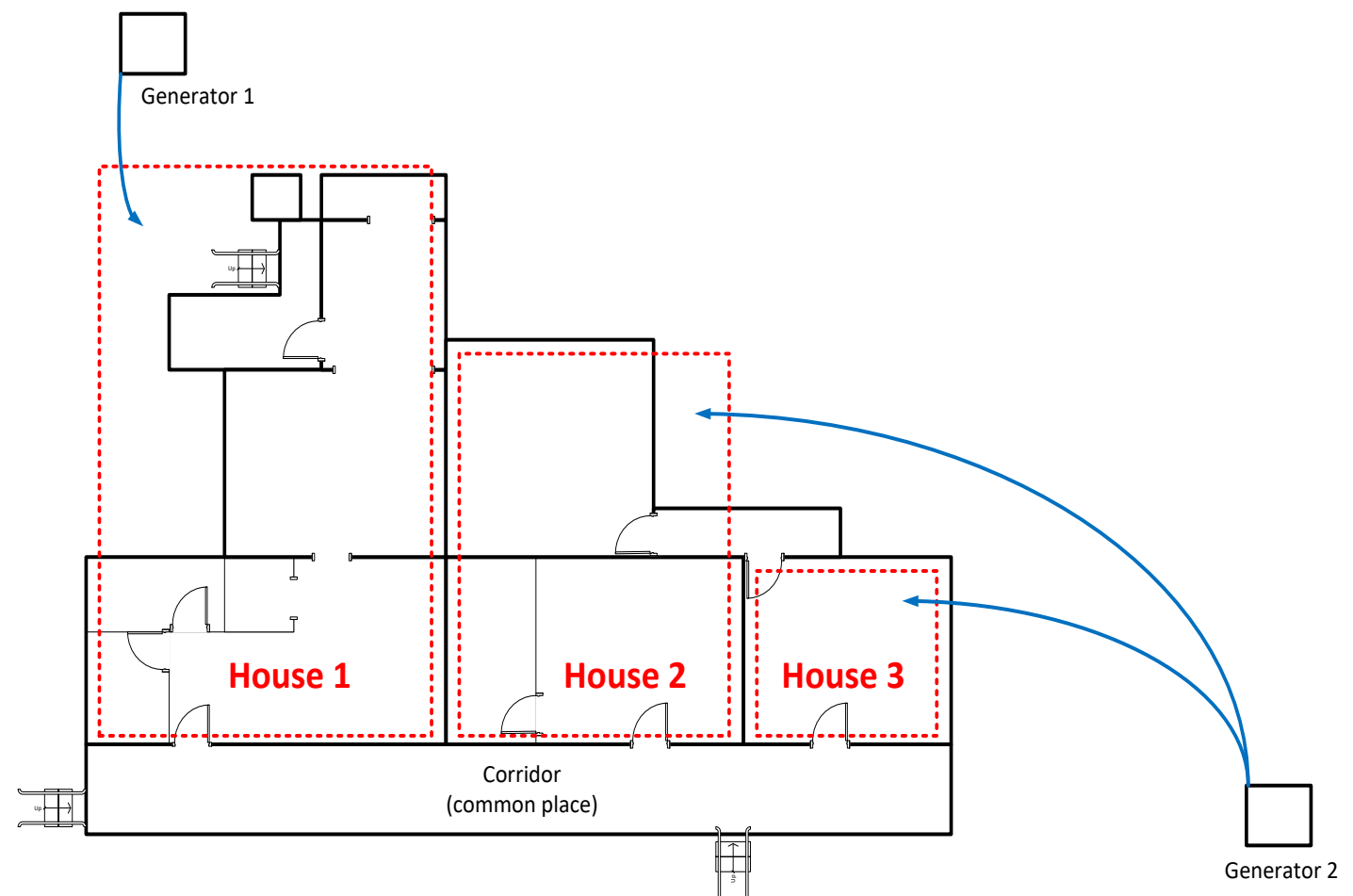

Figure 2. Classification of three houses and sources of electrical supply 


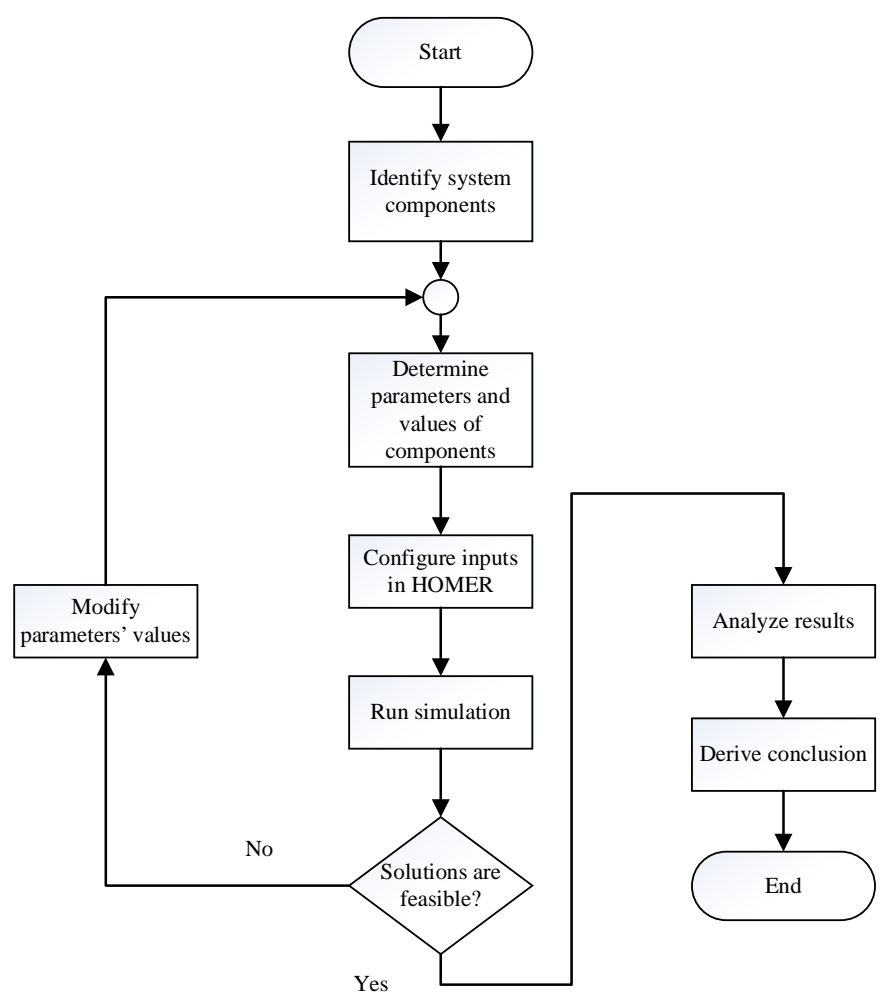

Figure 3. Flowchart of the design

Table 1. Loads for Long Houses in Kampung Sungai Merah

\begin{tabular}{|c|c|c|c|c|c|c|}
\hline House & $\begin{array}{l}\text { Electrical } \\
\text { appliance }\end{array}$ & $\begin{array}{c}\text { Power } \\
\text { per } \\
\text { hour } \\
(W)\end{array}$ & $\begin{array}{c}\text { Average } \\
\text { usage } \\
\text { (h/ } \\
\text { day) }\end{array}$ & $\begin{array}{l}\text { Usage for } \\
1 \text { unit per } \\
\text { day (Wh) }\end{array}$ & $\begin{array}{c}\text { Number } \\
\text { of unit }\end{array}$ & $\begin{array}{c}\text { Total usage for } \\
1 \text { house per } \\
\text { day (Wh) }\end{array}$ \\
\hline \multirow{6}{*}{1} & $\begin{array}{c}\text { Compact } \\
\text { fluorescent light } \\
\text { bulb } 1\end{array}$ & 26 & 5 & 130 & 1 & 130 \\
\hline & $\begin{array}{c}\text { Compact } \\
\text { fluorescent light } \\
\text { bulb } 2\end{array}$ & 20 & 5 & 100 & 1 & 100 \\
\hline & $\begin{array}{c}\text { Compact } \\
\text { fluorescent light } \\
\text { bulb } 3\end{array}$ & 18 & 5 & 90 & 7 & 630 \\
\hline & CRT television & 72 & 5 & 360 & 1 & 360 \\
\hline & Table fan & 48 & 6 & 288 & 2 & 576 \\
\hline & $\begin{array}{c}\text { Ceiling fan } \\
\text { Compact }\end{array}$ & 60 & 6 & 360 & 1 & 360 \\
\hline \multirow[t]{3}{*}{2} & $\begin{array}{l}\text { fluorescent light } \\
\text { bulb }\end{array}$ & 18 & 5 & 90 & 8 & 720 \\
\hline & LCD television & 50 & 5 & 250 & 1 & 250 \\
\hline & $\begin{array}{l}\text { Table fan } \\
\text { Compact }\end{array}$ & 48 & 6 & 288 & 1 & 288 \\
\hline \multirow[t]{2}{*}{3} & $\begin{array}{l}\text { fluorescent light } \\
\text { bulb }\end{array}$ & 18 & 5 & 90 & 3 & 270 \\
\hline & Table fan & \multicolumn{4}{|c|}{ TOTAL } & $\begin{array}{c}288 \\
3972\end{array}$ \\
\hline
\end{tabular}


Then, the design will be simulated to find feasible solutions. If feasible solutions are unable to be obtained, suitable values of parameters used in the system must be determined again. The feasible solutions will be analyzed and finally conclusion can be derived especially by highlighting the most optimal design. The proposed configuration of the system is shown in Figure 4. It contains PV source, converter, battery and loads. The detailed specifications of each of them will be described later. The converter is required since the system has both AC and DC elements.

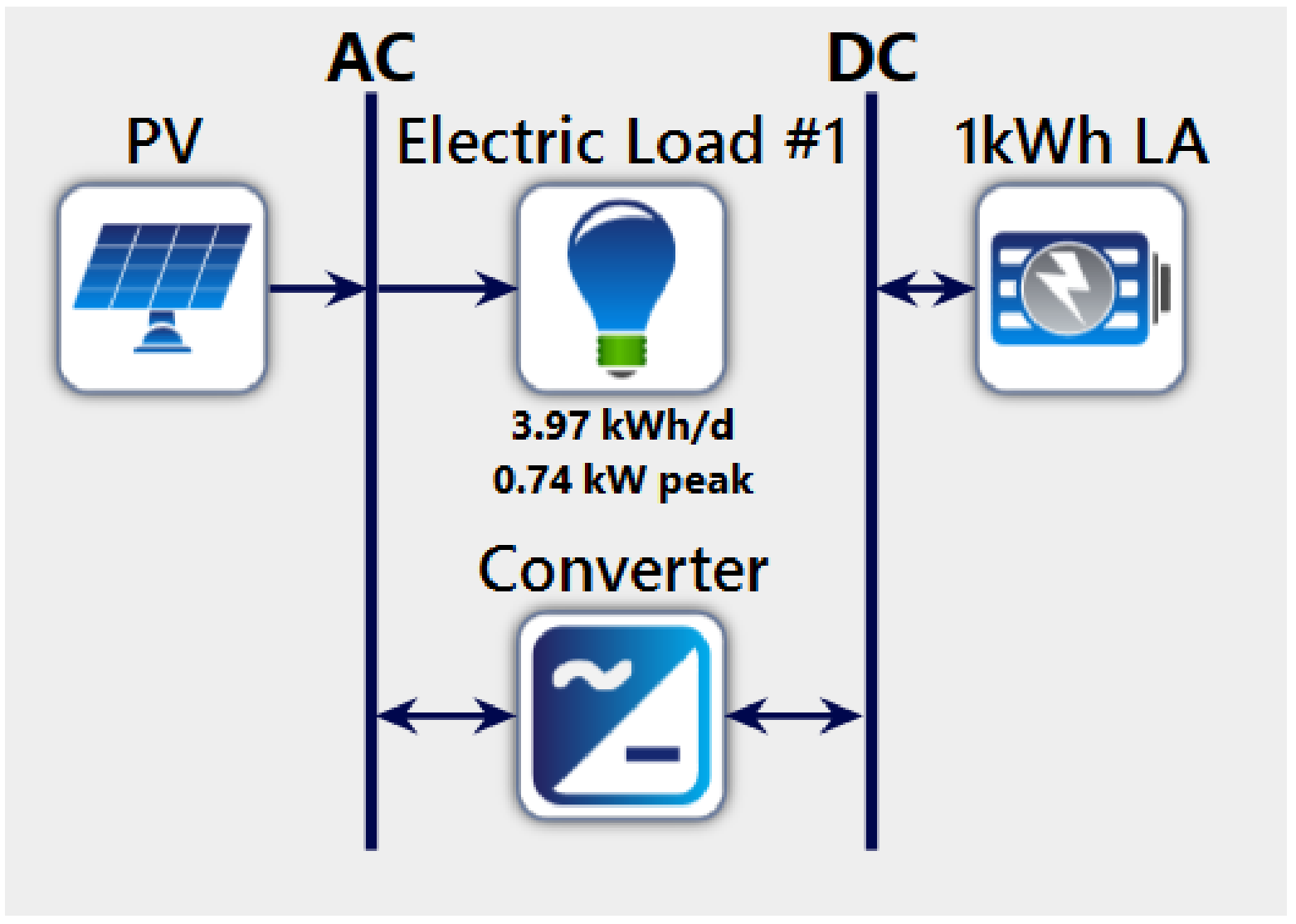

Figure 4. Configuration of the system

\section{Meteorological and Climate Data}

The collected data in this work for solar radiation on horizontal surface and wind speed at $10 \mathrm{~m}$ from ground are conducted based on NASA's Atmospheric Science Data Centre for 22 years. The long-term data are better for systems with long lifetime [9]. Interestingly in HOMER, this data can be obtained directly by configuring the resources, which are connected directly to the database. Monthly average solar irradiance data for Kampung Sungai Merah are shown in Figure 5, with their annual average irradiance is about 4.62 $\mathrm{kWh} / \mathrm{m}^{2} /$ day.

\section{Specifications of System}

Three main components proposed and discussed for the system with their specifications include PV module, battery and converter, as shown in Table 2. A PV module of $200 \mathrm{~W}$ is recommended for this work. Operation and maintenance cost is considered $1 \%$ of PV module price [10]. 


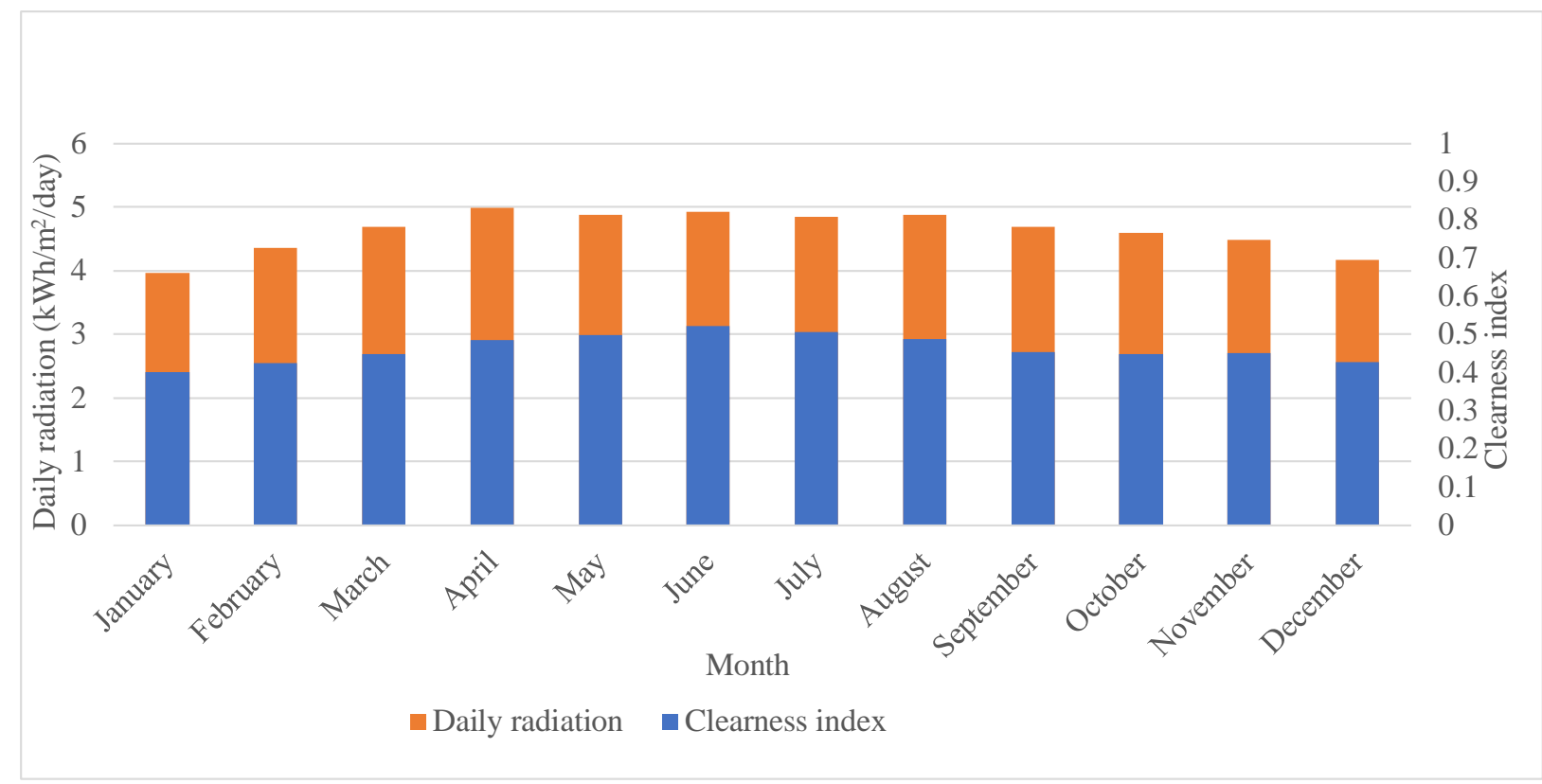

Figure 5. Solar irradiance data for Kampung Sungai Merah

Meanwhile, the maintenance cost of battery is assumed USD 10 per year respectively [11]. A converter is required for the developed system in which DC components serve an AC load or vice-versa. The converter can be inverter (DC to AC) or rectifier (AC to DC).

Table 2. Specifications of PV Module, Battery and Converter

\begin{tabular}{cc} 
Parameter & Value \\
\hline PV module & 200 \\
Nominal power (Wp) & 200 \\
Price (USD) & 25 \\
Lifetime (year) & 2 \\
Operation and maintenance cost (USD/year) & 1000 \\
Battery & 300 \\
Nominal capacity (Wh) & 10 \\
Price (USD) & 10 \\
Lifetime (year) & 80 \\
Operation and maintenance cost (USD/year) & \\
Efficiency (\%) & 1000 \\
Converter & 300 \\
Nominal power (W) & 10 \\
Price (USD) & \\
Lifetime (year)
\end{tabular}

\section{Simulation Configuration}

HOMER contains three main parts, which are simulation, optimization and sensitivity analysis. HOMER simulates the operation of a system by making energy balance calculations in each time step of the year. For each time step, HOMER calculates the flows of energy to and from each component of the system. For a system that includes batteries, 
HOMER also decides in each time step how to operate the generators and whether to charge or discharge the batteries. HOMER performs these energy balance calculations for each system configuration. It then determines whether a configuration is feasible and estimates the cost of installing and operating the system over the lifetime of the project.

As mentioned, HOMER software tool used in this work comes with the optimization algorithm using a proprietary derivative free algorithm to search for the least cost system. HOMER then displays a list of configurations, sorted by net present cost (NPC), or sometimes called life cycle cost, that can be used for comparing system design options. Finally, in sensitivity analysis, by defining sensitivity variables as inputs, HOMER repeats the optimization process for each sensitivity variable. In the simulation setup, this work considers optimization variables and sensitivity input as shown in Table 3. The optimization variables can be set by providing the possible range of each component's rating. The calculation process later will consider all possible values in the defined ranges. The selected sensitivity input is discount rate which will provide deeper analysis and specifically in this case, on economical approach which directs the designer to have better idea in term on finding the optimal system with reasonable cost. The discount rate refers to the interest rate used in discounted cash flow analysis to determine the present value of future cash flows. The discount rate takes into account not just the time value of money, but also the risk or uncertainty of future cash flows. The greater the uncertainty of future cash flows, the higher the discount rate.

Table 3. Details of Optimization Variables and Sensitivity Inputs

\begin{tabular}{cccc}
\multicolumn{3}{c}{ Optimization Variable } & Sensitivity Input \\
\hline Converter & Battery & Photovoltaic & Nominal Discount $(\%)$ \\
$0-5 \mathrm{~kW}$ & $0-15 \mathrm{kWh}$ & $0-10 \mathrm{~kW}$ & 3,6 and 12 \\
\hline
\end{tabular}

\section{Simulation Results}

The simulation work covers three sensitivity inputs, $3 \%, 6 \%$ and $12 \%$, which are not for intention of highlighting which one is the best, rather than to show their impacts on design outcomes. The simulation results which cover both optimization and sensitivity case are shown in Table 4. According to the results, in order to develop the proposed system, the PV source with $100 \%$ renewable fraction must be in capacity of $2.39 \mathrm{~kW}, 7$ units of $1 \mathrm{kWh}$ lead acid battery, and converter with rating of $0.67 \mathrm{~kW}$, for both rates of $6 \%$ and $12 \%$, while higher rating of PV (2.72 kW), lower batteries (6 units), and smaller converter ( $0.6 \mathrm{~kW})$, for rate of $3 \%$. Meanwhile, dispatch strategy for all rates is by using cycle charging approach, which lets the PV source to operate for serving the identified loads at full output power. Surplus electrical production goes toward the lower-priority objective by charging the battery.

As mentioned earlier, the higher the uncertainty of future cash flows, the discount rate will be increased. At the lowest discount rate, higher PV capacity is needed as to ensure it is reliable to supply enough power, as to reduce the uncertainty. Meanwhile, the battery needs regular replacement due to its shorter lifetime, which causes lower capacity of battery with the lowest rate. At higher discount rate, it is acceptable to decrease the installed capacity of PV, and the battery is increased. This adjustment is due to ability of considering higher uncertainty.

Meanwhile, the cost of energy (COE) (cost per kWh) is USD 0.403 for rate of 3\%, and further higher with USD 0.47 and USD 0.624 , for rates of $6 \%$ and $12 \%$ respectively. The lowest COE with the lowest rate is clearly due to higher usage of PV, as it is taking sun 
as free source of energy. With the lowest rate too, operating cost is high with USD 288.22, further down to USD 285.29 and USD 268.22 for the other two rates respectively. Initial capital is USD 4,704 for rate of 3\%, but same for the other two rates, with only USD 4,686. The operating cost is higher for the lowest rate as PV with larger capacity will involve more components for maintenance. In addition, expensive price for PV causes the initial capital to be higher.

Table 4. The Optimized Results from Simulation for Kampung Sungai Merah with Three Different Sensitivity Values

\begin{tabular}{cccc} 
Component/Parameter & \multicolumn{3}{c}{ Sensitivity/Discount Rate (\%) } \\
\hline System/Renewable fraction (\%) & 3 & 6 & 12 \\
Architecture/PV (kW) & 100 & 100 & 100 \\
Architecture/1kWh LA & 2.72 & 2.39 & 2.39 \\
Architecture/Converter (kW) & 6 & 7 & 7 \\
Architecture/Dispatch & 0.6 & 0.67 & 0.67 \\
Cost/Cost of energy (COE) (USD) & Cycle & Cycle & Cycle \\
Cost/Operating cost (USD) & 0.403 & 0.470 & 0.624 \\
Cost/Initial capital (USD) & 288.22 & 285.29 & 268.22 \\
PV/Capital cost (USD) & 4,704 & 4,686 & 4,686 \\
PV/Production (kWh) & 2,723 & 2,385 & 2,385 \\
1kWh LA/Autonomy (hour) & 3,665 & 3,210 & 3,210 \\
$1 \mathrm{kWh}$ LA/Annual throughput (kWh) & 22 & 25 & 25 \\
Converter/Rectifier mean output (kW) & 840 & 851 & 851 \\
Converter/Inverter mean output (kW) & 0.08 & 0.1 & 0.1 \\
Cost/Net present cost (NPC) (USD) & 9,723 & 8,333 & 6,789 \\
\hline
\end{tabular}

Further detailed data for PV are its capital costs (USD 2,723 for 3\% and USD 2,385 for both $6 \%$ and 12\%) and productions per year (3,665 kWh for 3\% and both with 3,210 $\mathrm{kWh}$ ). The configuration of battery with rate of $3 \%$ has its autonomy to work alone in only 22 hours of supplying the loads, which can be better for the other rates with 25 hours. Higher system capability for both $6 \%$ and $12 \%$ has caused the annual throughput to be about 851 $\mathrm{kWh}$, higher than rate of $3 \%$, which is only $840 \mathrm{kWh}$. However, for all rates applied to the proposed converter, the rectifier mean output is $0.1 \mathrm{~kW}$ and the inverter mean output is 0.08 $\mathrm{kW}$.

Finally, in term of NPC, it is showing higher with USD 9,723 for 3\%, decreasing to only USD 8,333 for $6 \%$ and the lowest with only USD 6,789 for $12 \%$. The NPC is the single value which includes all costs and revenues that occur within the project lifetime, with future cash flows discounted to the present. It is somehow can be different with operating component and initial capital. The total NPC includes the initial capital cost of the system components, the cost of any component replacements that occur within the project lifetime, and the cost of maintenance. HOMER calculates the NPC of each component of the system, and the system as a whole [12]. Further evaluation has been carried out on investigating performance of PV, storage and converter for all rates. Performance of PV obtained in each month is shown in Figure 6. 


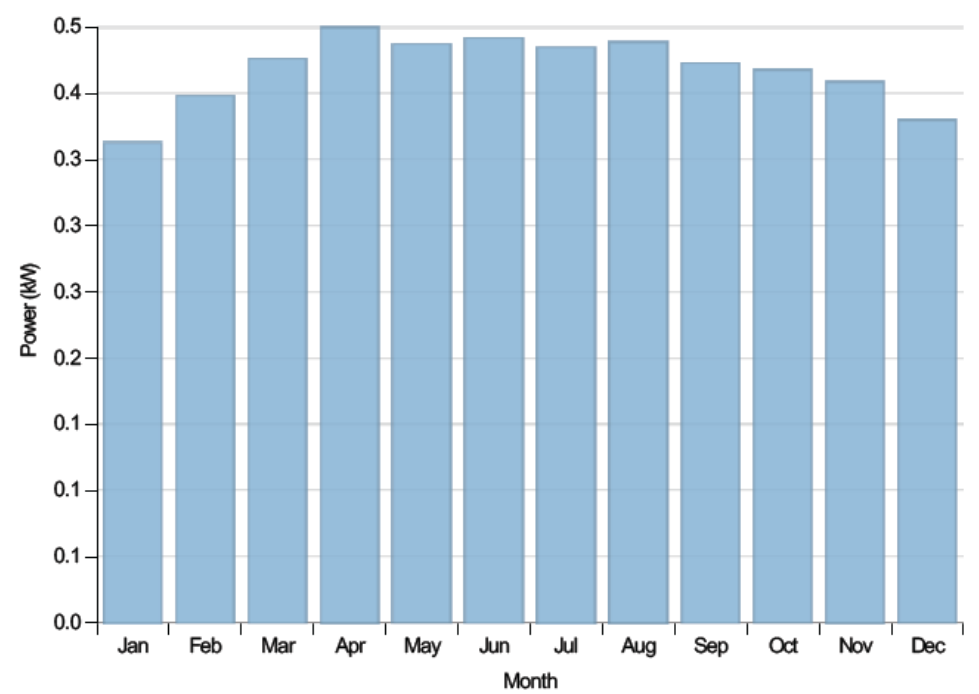

(a)

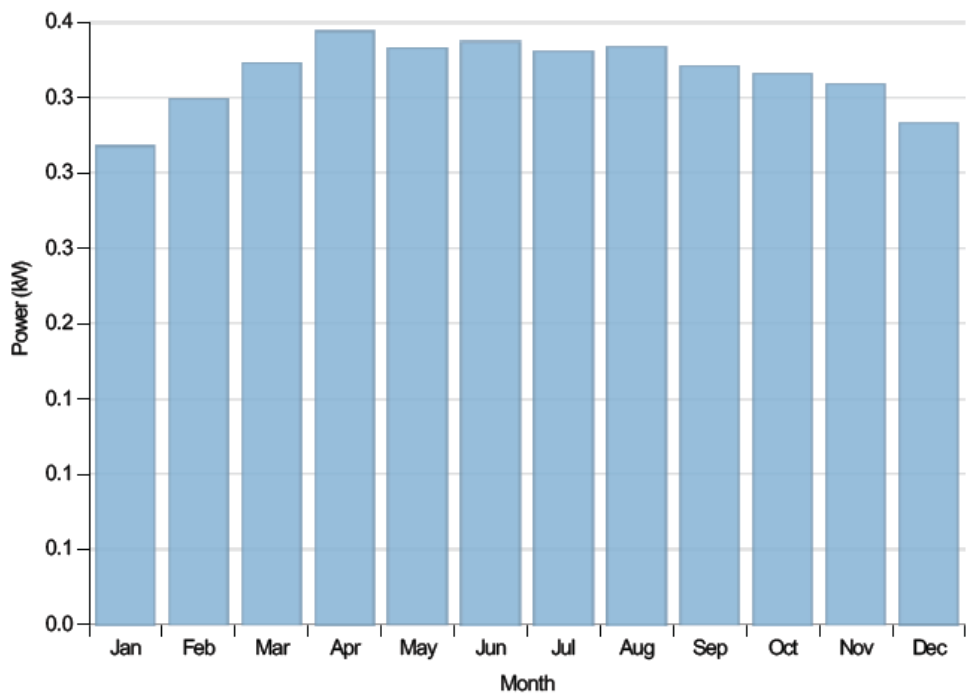

(b)

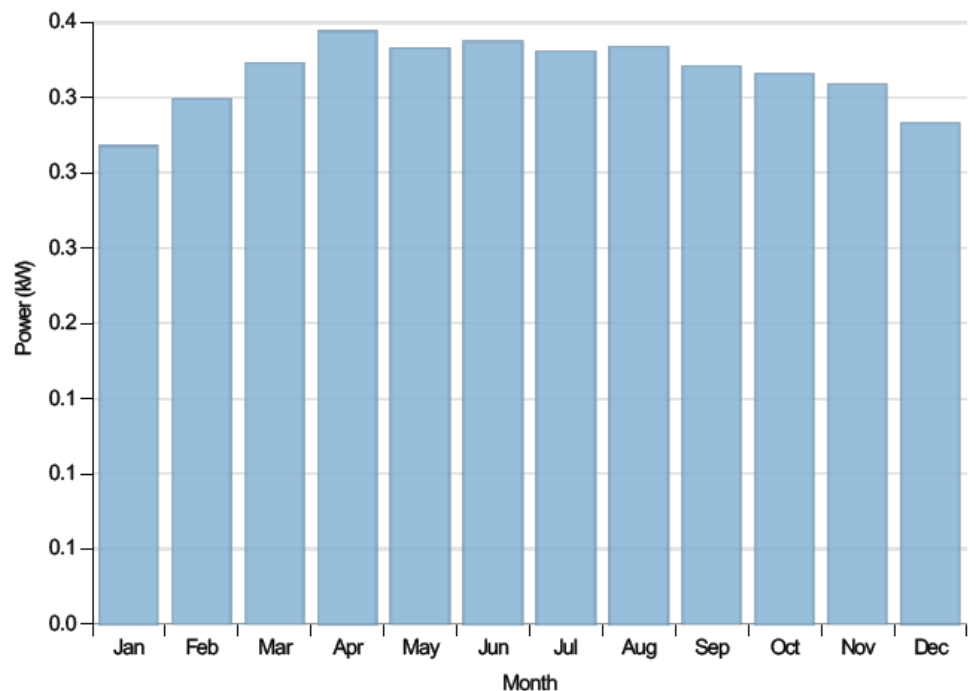

(c)

Figure 6. Output powers produced monthly from PV for rates of (a) 3\%, (b) 6\% and (c) $12 \%$ 
The results obtained clearly reflect to amount of solar irradiance received as shown in Figure 5. As April is having the highest radiation, then the output power can be achieved up to $500 \mathrm{~W}$ for rate of $3 \%$ and almost $400 \mathrm{~W}$ for the other two rates. The total productions for a year is 3,665 kWh for 3\% with higher usage of PV, and 3,210 kWh for the other two rates. As the PV only operates when the solar energy is available, the estimation of its operation for a year is 4,368 hours for all rates.

Meanwhile, batteries connected in parallel with total of 6 units for rate of 3\% and total of 7 units for the other two rates contribute significant role on storing energy during high operation of PV while keeping to supply energy back to the loads when PV in weak operation or does not work at all. Their state of charge conditions is shown in Figure 7, simply implying that their highest levels are during operation of PV. Thus, as shown clearly by red color during morning to evening for almost $100 \%$ state of charge, the batteries are in good condition to supply later the loads with no possibility of batteries to fully discharge.

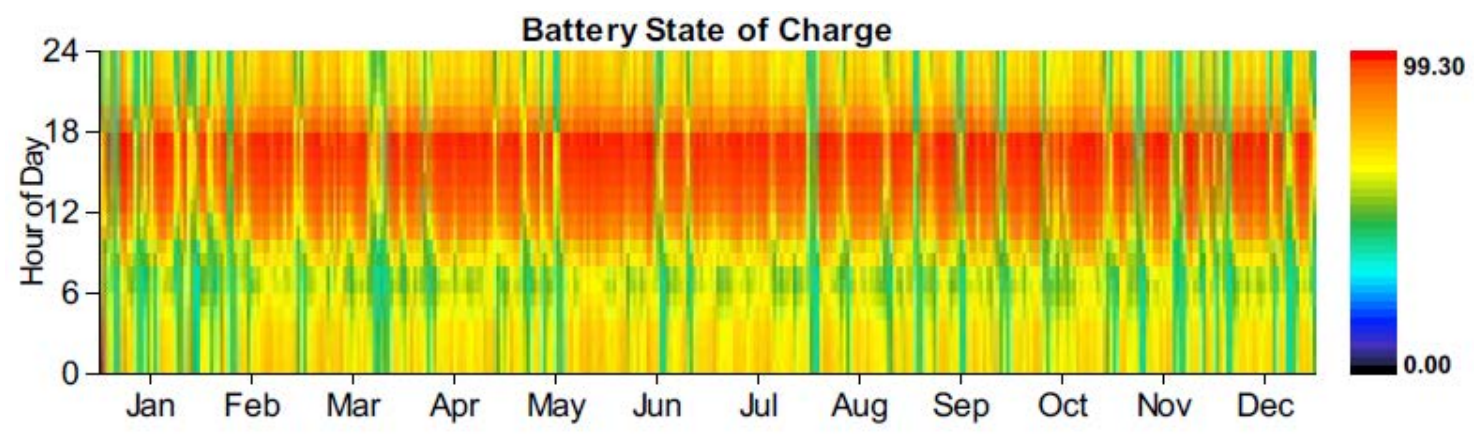

(a)

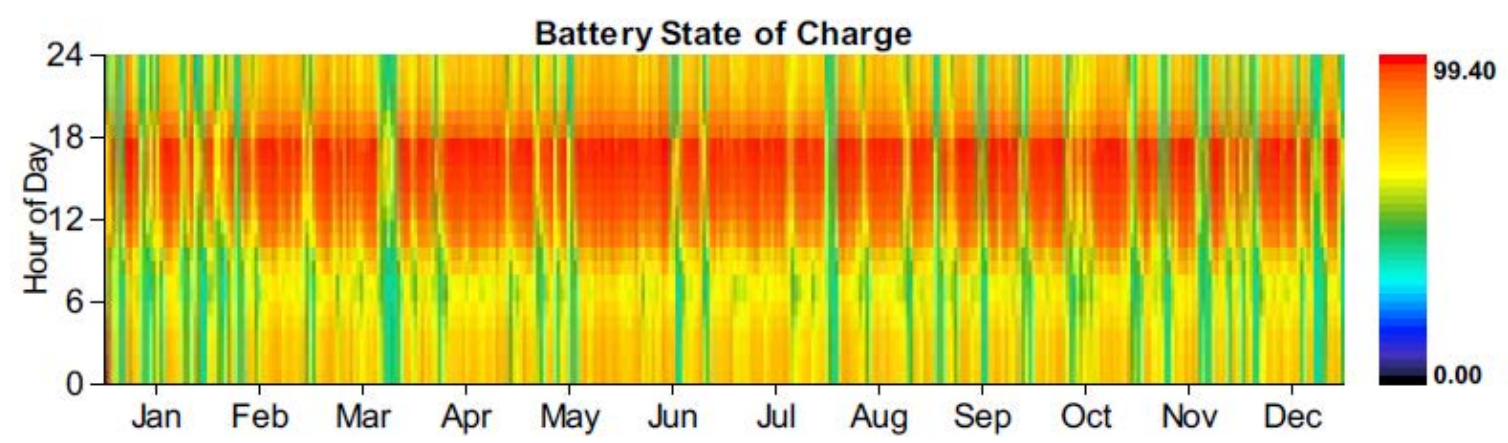

(b)

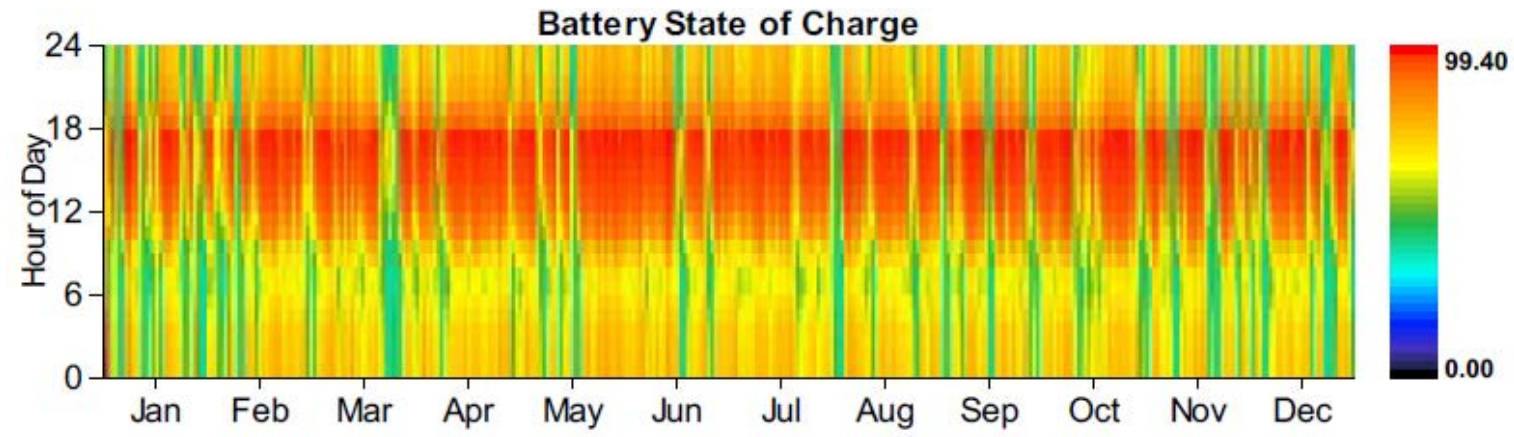

(c)

Figure 7. State of charge conditions of battery used in the system for rates of (a) $3 \%$, (b) $6 \%$ and (c) $12 \%$ 
Meanwhile, role of converter which contains both rectifier and inverter is also significant. Its operation is shown in Figure 8, by clearly implying different roles played by rectifier and inverter. When PV is in operation, rectifier will play the role by converting AC to DC to charge the batteries, as in cycle charging approach. Meanwhile, the inverter mainly

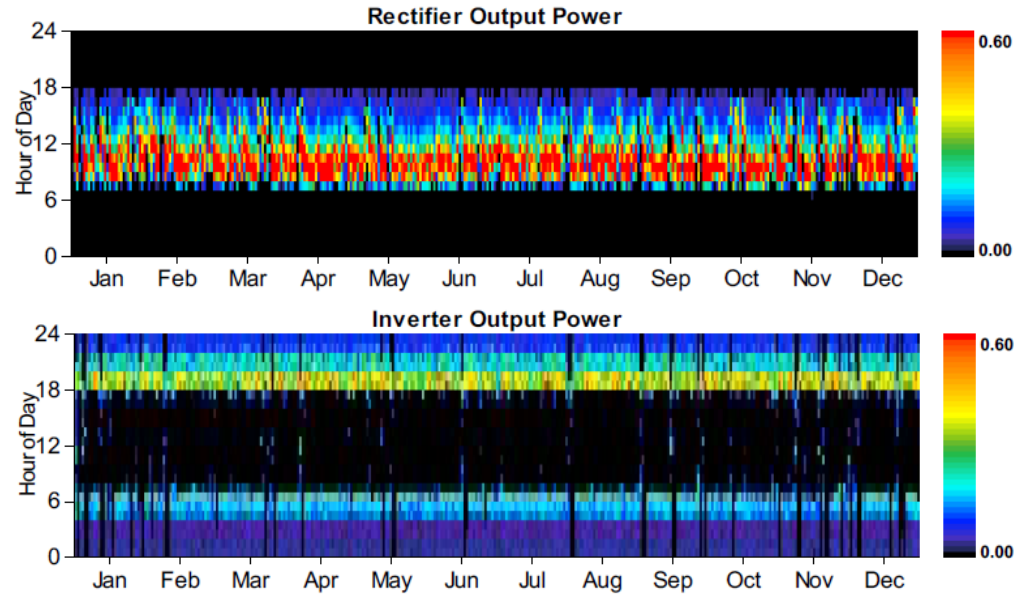

(a)

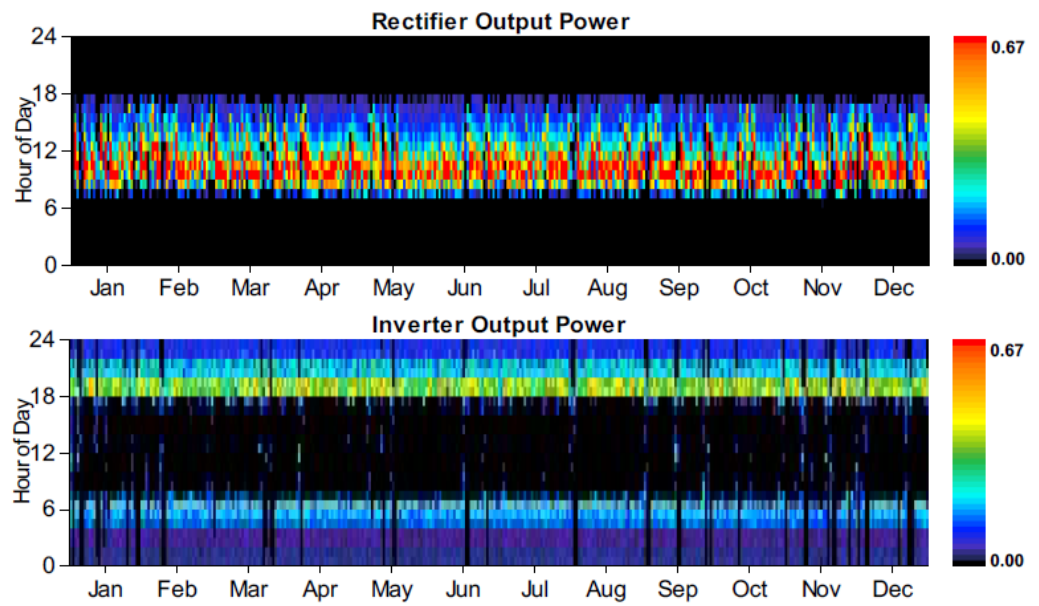

(b)
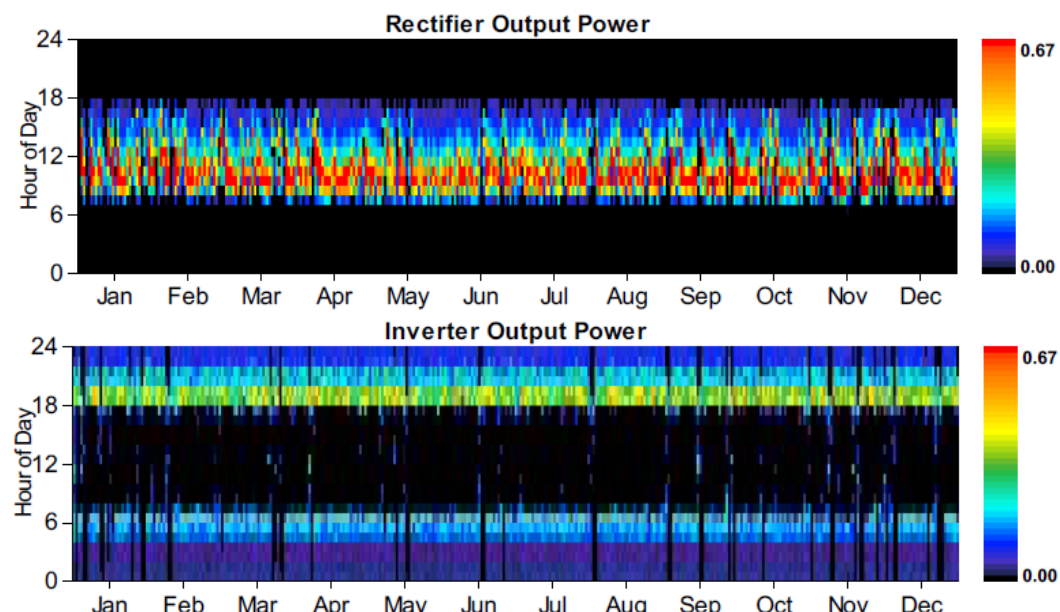

(c)

Figure 8. Performance of converter through output powers produced by rectifier and inverter for rates of (a) 3\%, (b) 6\% and (d) 12\% 


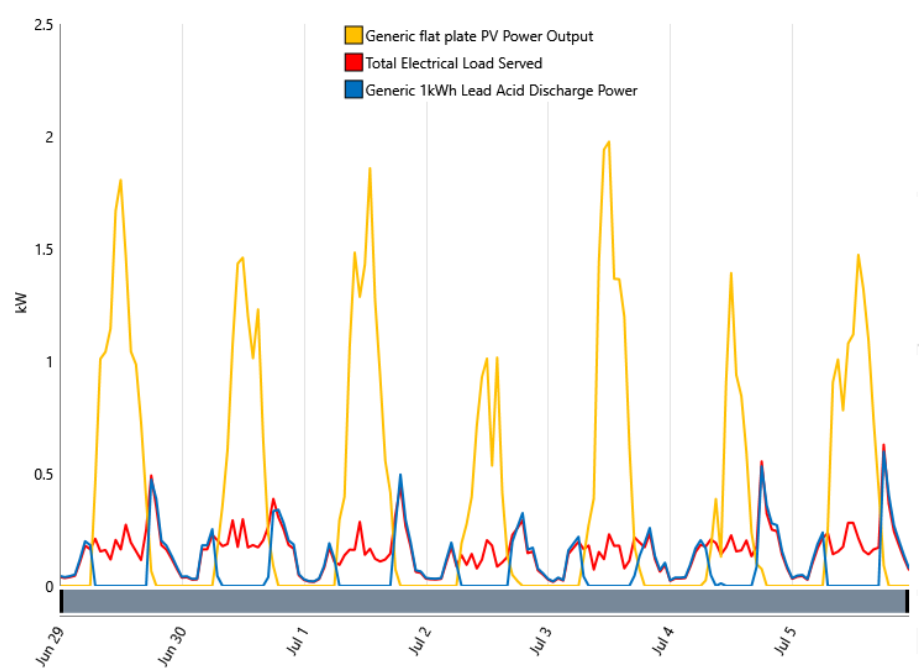

(a)

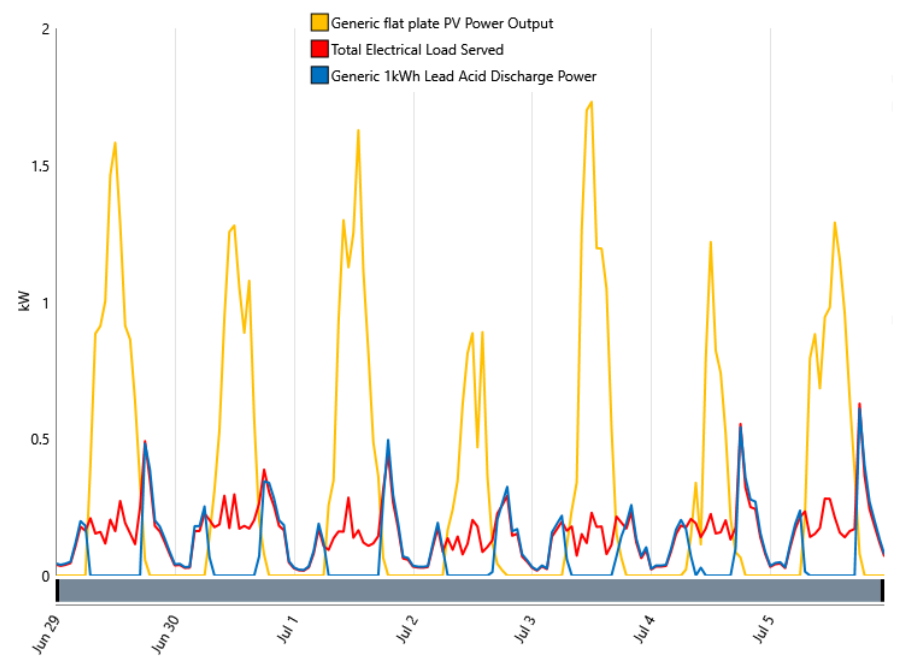

(b)

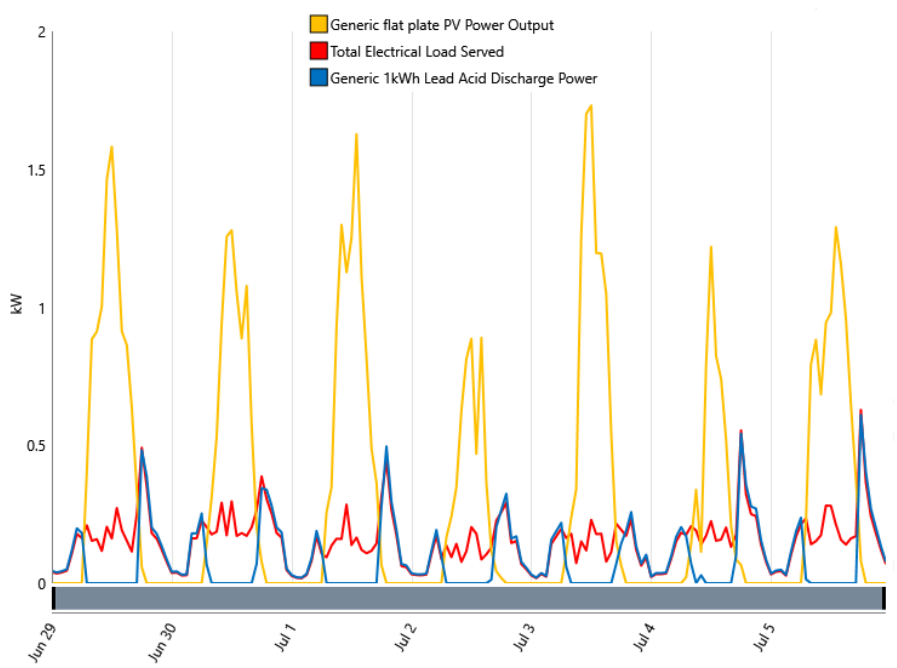

(c)

Figure 9. Daily load curves with corresponding outputs from PV and battery for rates of (a) $3 \%$, (b) $6 \%$ and (c) $12 \%$ 
operates to supply power from batteries to AC loads. Therefore, total operation hours of inverter are 5,057 hours (3\%) and 5,189 hours (other two rates), higher than rectifier with only 3,610 hours (3\%) and 3,531 hours (other two rates). Less operation hours of inverter for rate of $3 \%$ is due to less number of batteries used. In addition, for the rate of $3 \%$ too, higher PV installed contributes to higher operation of PV to charge the batteries. In term of impact of operation as can be seen in Figure 8 (shown by red color), rectifier contributes to higher power delivery within its operation periods.

In order to show daily load curves with corresponding outputs from PV and battery, measured samples taken based on operation from 29 June - 5 July have been considered. The samples in graphs are shown in Figure 9. From all graphs, the total load is fully served by PV during its higher production of power. Meanwhile, once the power from PV is not available, the role of supplying power will be replaced by battery. However, there is situation where limited power is supplied by PV, then balance of power is supplied by battery.

\section{Conclusions}

Estimation, design, simulation and optimization works have successfully been performed to finally produce optimal solar powered system for powering long houses in Sebuyau, Sarawak. Estimation of loads done directly from site visit has given significant contribution in ensuring the design and simulation work could present the most appropriate outcomes. In addition, meteorological data obtained in long period has also contributed to the most reliable results. Simulation done in HOMER has given optional outcomes, with three defined sensitivity values. From overall outcomes, this work should be to able to provide opportunity for the designer to fully consider various options in developing the best renewable and full solar powered system for rural electrification. Lower discount rate contributes to higher PV and lower battery architecture as compared to higher discount rates.

\section{Acknowledgement}

The authors would like to thank the Japan-ASEAN Science, Technology and Innovation Platform (JASTIP) Collaborative Research (JASTIP-Net 2016), Kyoto University for the financial support to this work.

\section{References}

[1] Economic Planning Unit, 11th Malaysia Plan (2016-2020), Prime Minister's Department, Putrajaya, Malaysia, 2015.

[2] R. Sen, and S.C. Bhattacharyya, "Off-grid electricity generation with renewable energy technologies in India: An application of HOMER,” Renewable Energy, Vol. 62, pp. 388-398, 2014.

[3] H.A. Kazema, T. Khatib, and K. Sopian, "Sizing of a standalone photovoltaic/battery system at minimum cost for remote housing electrification in Sohar, Oman,” Energy and Buildings, Vol. 61, pp. 108-115, 2013.

[4] Al-Karaghouli, and L.L. Kazmerski, "Optimization and life-cycle cost of health clinic PV system for a rural area in southern Iraq using HOMER software,” Solar Energy, Vol. 84, No. 4, pp. 710-714, 2010.

[5] Yahyaoui, A. Atieh, A. Serna, and F. Tadeo, "Sensitivity analysis for photovoltaic water pumping systems: Energetic and economic studies," Energy Conversion and Management, Vol. 135, pp. 402-415, 2017. 
[6] Alsheghri, S.A. Sharief, S. Rabbani, and N.Z. Aitzhan, "Design and cost analysis of a solar photovoltaic powered reverse osmosis plant for Masdar Institute,” Energy Procedia, Vol. 75, pp. 319 - 324, 2015.

[7] M. Fadaeenejad, M.A.M. Radzi, M.Z.A.A. Kadir, and H. Hizam, “Assessment of hybrid renewable power sources for rural electrification in Malaysia," Renewable and Sustainable Energy Reviews, Vol. 30, pp. 299-305, 2014.

[8] A. Ghafoor, and A. Munir, "Design and economics analysis of an off-grid PV system for household electrification," Renewable and Sustainable Energy Reviews, Vol. 42, pp. 496-502, 2015.

[9] F. Vignola, C. Grover, N. Lemon, and A. McMahan, "Building a bankable solar radiation dataset,” Solar Energy, Vol. 86, No. 8, pp. 2218-2229, 2012.

[10] Dirk Jordan, “Survey of PV Field Experience,” Utility/Lab Workshop on PV Technology and Systems, November 2010, [PowerPoint slides], Retrieved from http://www.nrel.gov/docs/fy11osti/49854.pdf

[11] R. Dufo-López, and J.L. Bernal-Agustín, "Multi-objective design of PV-wind-dieselhydrogen-battery systems,” Renewable Energy, Vol. 33, No. 12, pp. 2559-2572, 2008.

[12] W. M. Amutha, and V. Rajini, "Cost benefit and technical analysis of rural electrification alternatives in southern India using HOMER," Renewable and Sustainable Energy Reviews, Vol. 62, pp. 236-246, 2016. 